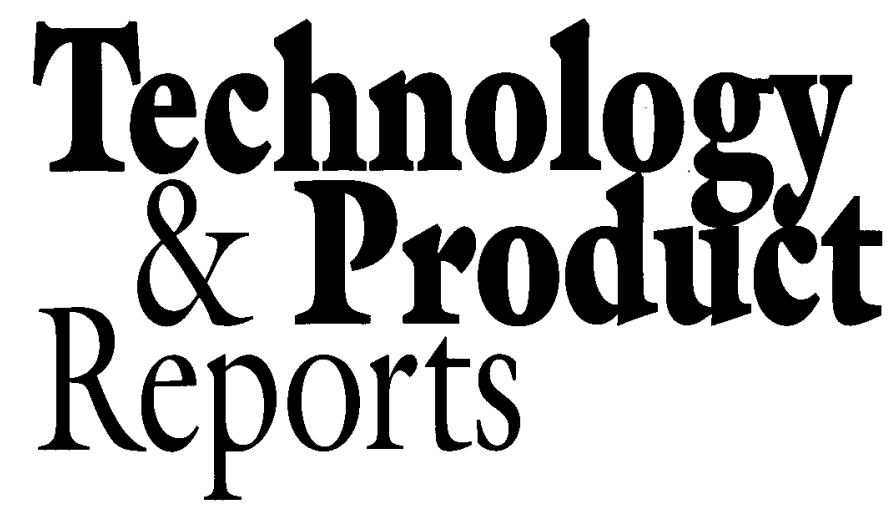

using Palmtop Computers to Collect Plant Data in the Field

\author{
Laura Lehman-Salada', \\ K. Hickey ${ }^{2}$, and T. Salada ${ }^{3}$
}

Additional index word. computer applications

Summary. Agricultural research often involves collecting numerical data in the field, orechard or greenhouse. Traditionally, horticulturists have recorded numerical data by hand and then manually entered the information into a computer or calculator for statistical analysis. In the last decade data loggers and portable computers have made data collection and analysis easier and more efficient. A palmtop computer is a small, lightweight instrument that combines the best characteristics of data loggers and portable computers. In our trial, palmtop computers equipped with a spreadsheet software program were ideal for numerical data entry in the field and were a costeffective alternative to other devices.

${ }^{1}$ Research associate in pomology.

${ }^{2}$ Professor of plant pathology.

${ }^{3}$ Project associate.

Pennsylvania State University (PSU), Fruit Research and Extension Center, PO Box 309, Biglerville, PA 17307-0309. PSU Horticulture Dept. series no. 278. This research was supported in part by agricultural research funds administered by Pennsylvania Dept. of Agriculture (PDA). Use of trade names and vendors in this paper does not imply endorsement by PSU or PDA, nor criticism of similar products or vendors not mentioned. The cost of publishing this paper was defrayed in part by the payment of page charges. Under postal regulations, this paper therefore must be hereby marked advertisement solely to indicate this fact.
$\mathrm{H}$ orticulturists often collect experimental data in the orchard, field, greenhouse, or laboratory by recording each measurement or observation by hand onto a data sheet. Information gathered in this manner is then entered into a computer file or calculator for statistical analysis. Although manual recording is uncomplicated and adaptable to a variety of settings, it can be time-consuming and less efficient than other methods of data collection.

\section{Data loggers}

One alternative is to use a portable, electronic data logger that allows information to be entered into user-specified categories, such as treatment, replicate, and measurement. These durable instruments usually have numerical keys and several function keys, thus providing a simple layout for rapid entry. Many models have a display screen with $<200$ characters to assist the user in verifying each entry as it is made. Collected data usually is transferred to a desktop computer for subsequent analysis and archiving.

Some loggers are equipped with a common DOS (disk operating system ) installed before purchase, so information can be gathered in a computer format compatible with the desktop computer chosen to receive the file. Examples of loggers include the DataFielder 200 (Kaye Instruments, Bedford, Mass.), QTerm II (QSI, Salt Lake City, Utah), and FieldBook (HarvestMaster, Logan, Utah).

For studies involving repeated measurements over time, some data loggers have a laser or visible light reader that can scan a barcode on each experimental unit (e.g., plants or plant parts). Examples include the OmniWand (Videx, Corvallis, Ore. ) and MEQ portable data terminal (Mars Electronics International, West Chester, Pa. ).

Disadvantages associated with some data loggers include relatively small character size (if a screen is present) and limited battery and memory capacity. The absence of notetaking software on many loggers is particularly vexing when factors other than the imposed treatments are suspected of influencing the experimental results. Loggers are sometimes used by plant breeders, although specific field observations of plant selections must be converted to numerical ratings for data collection.

\section{Portable computers}

Some horticulturists prefer to use portable computers with standard keyboard formats (QWERTY) as data-entry terminals in the field. These devices are generally smaller $(<20$ inches on the diagonal when opened) and lighter $(<10$ pounds) than desktop computers. Three major classes, in order of largest to smallest, are notebook, subnotebook, and palmtop computers.

Using a portable computer, data can be collected for several days or weeks before downloading is required. In some cases, no downloading is necessary because data collection and analysis can be performed on the portable computer. Display screens on notebook and subnotebook computers are usually larger and easier to read than those on data loggers.

Notebook computers are marketed as tools for business executives who travel frequently. Because these computers are designed primarily for use on a horizontal surface in a room with a relatively narrow temperature and humidity range, they may perform poorly in a harsh environment such as a hot, humid greenhouse. In addition, problems may arise due to instrument weight and size. When used in field studies with widely spaced experimental units, portable computers can be somewhat cumbersome to carry. Some screens are difficult to view clearly in bright sunlight, especially if the screen angle and contrast are not adjustable.

\section{Palmtop computers}

In the last decade, several companies have introduced small, portable computers, including personal organizers and palmtop computers. Personal organizers, such as the Newton 
Apple Message Pad (model 110;Apple Computer, Cupertino, Calif.), rely primarily on an electronic pen instead of a keypad to enter information (Mann, 1994; Young and Kleiner, 1994). Palmtop personal computers are small (usually $<6 \times 8$ inches when opened), lightweight ( $<1$ pound), and relatively durable (Mann, 1994; Young and Kleiner, 1994). Palmtops usually have a fill keyboard with numeric and alphabetic keys and, if equipped with enough memory, are capable of running software programs similar to those available for large computers (Young and Kleiner, 1994). Scientists involved in quality assurance programs in food-processing plants have reported that palmtops are also useful in a laboratory setting (Martz, 1993).

We have used palmtops (model 100LX; Hewlett-Packard, Corvallis, Ore. ) for tabulating disease lesion incidence on attached apple leaves in an orchard. For 4 months we used palmtops to collect several hundred pages of data with 150 to 200 entries per page.

A template for each experiment was created on a desktop computer and then downloaded to the palmtops. The template consisted of information that identified the experiment, cultivar, tree, spur number, and each disease of interest. Templates were fixed on each palmtop so that column headings were always visible on the screen when a user scrolled to any row on the spreadsheet. Field modification of the spreadsheet, such as adding a column or changing column width, was accomplished with two or three keystrokes. At the end of each working day, users downloaded the data to a desktop computer, but could have collected data for several weeks before downloading became necessary.

The palmtops we used were relatively easy to master. After a 2-h instruction session, three employees with minimal computer experience learned enough commands to begin gathering data in the orchard. The transition from recording information on paper to using palmtops was not difficult because the computers that we tested were equipped with a common spreadsheet program (Lotus 1-2-3, Lotus Development, Cambridge, Mass. ) installed on the hard drive.

In our trial, letter and number size on the palmtop screen were judged acceptable for use in the field, but some users may prefer to use software that increases character size. The screen ( $80 \times 25$ characters) on the model we tested was easy to read on sunny and cloudy days because the screen angle and contrast were readily adjustable.

Unlike most data loggers, palmtop and notebook computers can be used to collect numerical data and notes in the field. In our trial, brief observations were recorded in a text file and then downloaded to a desktop computer along with the data file. This approach was useful to explain an occasional missing spur or perhaps an unexpected result of a treatment. If data and text files are named and saved initially, users can move quickly between the two files without repeated saving and closing.

Small key size could be a problem for palmtop users accustomed to the larger keys on notebook and desktop computers. Although our users reported few problems related to key size, palmtops are not particularly suitable for prolonged touch-typing (Mann, 1994; Resnick, 1992; Young and Kleiner, 1994). On our palmtops, unintentional keystrokes during data entry were few because all of the numeric keys are color-coded and are located in one section of the keyboard.

Most palmtops cannot transfer files on 3.5-inch floppy disks, but data and text files can be transferred to and from a desktop computer in minutes via cable or connectivity kit (Ihnatko, 1992 ). For the palmtop that we tested, files were moved as ASCII characters using a transfer protocol such as Kermit or XMODEM. We printed each data file before statistical analysis so that a hard copy could be scanned visually for obvious errors.

Because palmtop computers can be connected directly to a printer or another computer for file transfer, a data set can be printed immediately after collection and sent to colleagues involved in cooperative research projects. Most palmtops can be connected to a modem to allow file transfer by facsimile machine. Many are equipped to send and receive electronic mail messages (Bulkeley, 1991), but this maybe difficult for lengthy messages because of the relatively small screen. An adapter can be used to connect the palmtop to a network of other computers (Maxwell, 1994 ) or to access information on public databases and bulletin boards (Bulkeley, 1991).
Two megabytes of ROM (readonly memory) and RAM (randomaccess memory) on the palmtop were sufficient for manipulating data sets with 50 to 200 pages of data. Adding a Type II PCMCIA (personal computer memory card international association) card increases the nonvolatile memory capacity 10 to 15 times the base capacity ( Leyenberger, 1994). If current trends continue, new palmtops will be equipped with nearly as much memory as low-end desktop computers.

Most palmtops contain several primary and backup batteries and have a dependable warning system that tells the user when each power source becomes low. Most models conserve power by automatically shutting off after several minutes with no keystrokes. Even if the computer is turned off accidentally without intentionally saving newly entered data, many palmtops have a builtin save feature to prevent data loss. For use in the laboratory, an alternating current power adapter can be used to conserve battery life.

Our experience with palmtop computers indicated that they are a useful alternative to data-acquisition devices and notebook computers for gathering plant data in the field. Palmtops were affordable, easy to use, saved time, and had other features useful to busy scientific professionals. Several models currently on the market deserve consideration for use as reliable data-collection instruments.

\section{Literature Cited}

Bulkeley, D. 1991. HP palmtop: Power in a small package. Design News 47( 13):74-76.

Ihnatko, A. 1992. Have data, will travel. MacUser8(5):187-191.

Leyenberger, A. 1994. PCMCIA today. PC Laptop Computers Msg. 6(8):64-76.

Mann., R. O. 1994. Expert advice on how to choose and use the best notebook, palmtop, or PDA. Compute; J. Progressive Computing 16(5):53-64.

Martz, D. 1993. Implementing an electronic notebook data entry system at Hudson Foods. Sci. Computing Automation 9(11):15-16.

Maxwell, K. 1994. PCMCIA LAN adapters. PC Laptop Computer'sMag. 6(8):4447, 87. Resnick R. 1992. Palmtop strategies. Compute; J. Progressive Computing 14(10):83-86.

Young, K. and B.H. Kleiner. 1994. N ew developments in palmtop computers. Intl. J. Computer Applications Technol. 7(1/ 2):78-80. 